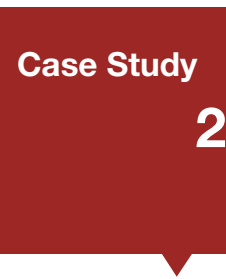

\section{Development of a Model Policy for \\ Research Data Management (RDM) \\ at Austrian Research Institutions}

Authors: Paolo Budroni, (Project Director, e-Infrastructures Austria), Barbara Sánchez Solís (Project coordinator, e-Infrastructures Austria) \& Imola Dora Traub (LEARN Project Coordinator) - University of Vienna

Email: paolo.budroni@univie.ac.at / barbara.sanchez.solis@univie.ac.at

\subsection{BACKGROUND}

The establishment of a model research data management (RDM) policy for Austria is underway. On the one hand, this enterprise has been prompted by rising expectations in the research community, particularly in reaction to the Open Research Data Pillot from Horizon 2020, which has been running since 2014. On the other hand, the results of a comprehensive, quantitative survey regarding RDM in Austria were completed between January and March 2015, as part of the project e-Infrastructures Austria. ${ }^{1}$ Over 3000 researchers from 20 out of 21 public universities in Austria, as well as three non-university research institutions, took part in the survey this response reflected a $9 \%$ the res a than half of the survey participants expressed an explicit desire for guidelines and policies.

It is worth noting that, at the time of the survey, none of the participating Austrian institutions and none of the large national research grant foundations made use of an RDM policy. Only the Austrian Science Fund (FWF), the grant foundation, included a paragraph in its Open Access Policy dedicated to research data, which stated that "whenever legally and ethically possible, all research data and similar materials which are collected and/or analysed using FWF funds have to be made openly accessible". 3

In early 2016, in order to formulate requisite and explicitly-cited guidelines for competent RDM, the Projec Management of e-Infrastructures Austria created a "task force dedicated to finding strategies for the management of research data in Austria". During the lifespan of this expert group, the FWF called for an "Open Research Data Pilot".

The Expert Group comprised 22 members ${ }^{4}$ from the stakeholder groups including e-Infrastructures Austria government ministries, Universities Austria (UNIKO), Vice-Rectors of Research, national research-funding organizations, scientists, scientific libraries, IT-services and research services, and was organised by the Library and Archive Services of the University of Vienna. The Expert Group also tasked a nine-member working sub-group to develop a model for RDM policies in Austrian research institutions. The resulting model policy provides exemplary templates in both German and English, which can be adapted to suit the philosophy and needs of any research institution. This model for RDM policy is the result of six months of collaborative work, and was completed during a meeting of the Expert Group on 2 June 2016.

The Library and Archive Services of the University of Vienna worked concurrently with its partners on the
Implementation of the Horizon 2020 Project LEARN. 5 It proved advantageous that the leadership of the Work Package 3 (Policy Development and Alignment) of the LEARN Project and the leadership of e-Infrastructures Austria were active at the same time, and that both tasks were managed within the same organisation, i.e. the Library of the University of Vienna. For this reason, findings continually flowed back and forth between the expert groups of the two projects. Furthermore during this same period the first three (of five) LEARN workshops were held in London, Vienna and Helsinki, and focused on RDM and policy development.

\subsection{EVALUATION OF RDM-POLICIES IN THE SCOPE OF PROJECT LEARN}

Between July 2015 and June 2016, the Library of the University of Vienna collected and analysed over 40 European RDM policies. In the course of this preparation phase, it became obvious that in many countries (especially in continental Europe) there have hardly been any published quiding principles regarding RDM. After a further selection process, 20 policies were examined more closely based on (identified) format and content-related criteria. ${ }^{6}$ Using an analysis grid, 11 RDM policies from the United Kingdom, four from Germany, one from the Netherlands and four from Finland were evaluated and checked for possible significant changes during this period at regular intervals.

The most striking results from this analysis related to format and content: it was apparent that research institutions often draw on one another, and sometimes sources were even explicitly referenced. Authorship and the date of publication were not always explicitly stated, and standard formatting did not exist. More than half of the policies analysed made no mention of review periods or revision editions. It was universally clear which topics the policies addressed, and largely, to whom they applied. The concrete objectives of the policies were not directly declared in each case. Roles and responsibilities in research institutions were always mentioned, and in some cases were clearly assigned to specific stakeholders. Only very few institutions explicitly name students as stakeholders worthy of consideration. A position on research funders was taken by most institutions, although, with a few exceptions, costs were only indirectly mentioned.

The term "research data" was defined by most institutions, but the terms "research" and "researcher" only rarely; definitions of other key terms (such as "data management plan") were also rarely supplied. "Open data" as an issue was a universal concern (although to a varying extent), "restricted data" or "closed data" were mentioned in connection with ethical and legal concerns, if at all. In turn ethical and legal aspects were almost always mentioned, but with widely differing interpretations; in many cases, additional guidelines were referenced. Ownership of data was clearly formulated in about one quarter of the selected policies; it is worth noting, however, that although authorship is mentioned, very few delineations between copyright and rights to use were made.

On the topic of "storage and access" it was notable that data security and open access to research data were strongly emphasised, while long-term archiving was only sporadically mentioned. A specific location for the storage of data was, with a few exceptions, not named; although, some research institutions provide or recommend such services. Externally (with respect to a research project) generated and stored data should also be registered internally. The archival storage period for research data was addressed in about half of the examples analysed; the exact lengths of time, if declared, varied, but 10 years was the length of time most commonly cited. The explicit deletion of data was mentioned in only a very few examples, although 
this issue is best addressed by data management plans (DMP). A DMP was described in all examples (in some more thoroughly than others) or even considered as a mandatory requirement; in several policies there is evidence that a template was used, or a DMP-guidance tool (such as that of Digital Curation Centre).

The topic of "support and training" was universally treated as a necessary component of RDM and was mentioned in all policies. In contrast, the relevance of topics such as "educational data" and "cultura heritage" has not yet entered the consciousness of the research community.

\subsection{WORK OF THE EXPERT GROUP E-INFRASTRUCTURES AUSTRIA}

The Expert Group task force made use of previous data on the subject of RDM, including the results of the report entitled "Researchers and their Data: Results of an Austrian Survey", the results of the first LEARN workshop, held in London in January 2016, as well as the results of an online conference with universities in South America.

The Expert Group also formed a nine-person work sub-group, which met regularly every two weeks, and was charged with drafting a policy paper. At first, work was begun in English, as many of the existing policy examples were written in English. Over time, however, drafts were broken down to meet Austrian needs, in both language and meaning. The model policy became more and more concrete with each meeting. The project management of e-Infrastructures Austria ensured a continual flow of information between the work subgroup and the Project LEARN, particularly as the breakout sessions during the second and third workshops became more and more focused on policy development in varying European institutions. E-Infrastructures Austria also set a high standard with the organisation of the four-day "Training Seminar for Research Data Stewardship and e-Infrastructures", 7 which looked at operational measures in the field of RDM.

\section{The following duties of the Expert Group are of particular importance:}

- Regularly exchanging information regarding the development of a model RDM policy with LEARN project partners, particularly with representatives from

South America, in order to compare and standardise terminology

- Utilising the results of the breakout sessions of the LEARN Workshops;

- Keeping the goals and mission outlined in the LERU Roadmap in consideration:

- Upholding the "FAIR guiding principles for scientific data management and stewardship";;

- Gathering feedback from the Austrian research landscape, particularly with

regard to rights and organisational guidelines and terminologies;

- Involving institutional computer centres (ICT);

- Cooperating with legal experts;

- Continually exchanging information with representatives from Austrian research funders and sponsors:

- Comparing the results of the work sub-group with the conclusions drawn after the

examination of RDM policies across Europe (see also: Evaluation Grid for RDM

Policies in Europe. Survey results, August 2016 in this Toolkit, pp. 139-66).9

\subsection{CONCLUSION}

After the creation of a model policy, and in particular its customisation at the local level, many recommendations can be made to help establish efficient RDM at individual institutions. The establishment of RDM support services has proven indispensable. Therefore, the Expert Group also provided recommendations on an organisational and structural scale. In June 2016, the Expert Group decided to publish the model policy ${ }^{10}$ and to enter it in the Universities Austria (UNIKO) "Forum Research" for further comments. From the autumn of 2016 the recommendations will be addressed and local adaptations could begin.

Further documents related to this case study are: 1) Model policy for research data management (RDM) at Austrian research institutions; 2) LEARN Evaluation Grid for RDM Policies in Europe. Survey results, August 2016.11

\subsection{APPENDIX}

22 members of the task force dedicated to finding strategies for the management of research data in Austria Project e-Infrastructures Austria:

Mag. Maria Seissl, Library of the University of Vienna

Head of the Library and Archive Services of the University of Vienna, Coordination task force

Seyavash Amini, University of Hannover

Legal advisor, e-Infrastructures Austria

Mag. Bruno Bauer, Library of the University of Vienna, Medical University of Vienna Chair of the General Assembly, e-Infrastructures Austria

Mag. Dr. Andrea Braidt, Academy of Fine Arts Vienna Vice-Rector for Research

Univ. Prof. Dr. Gerhard Budin, University of Vienna Coordinator, Think Tank, e-Infrastructures Austria

Dr. Paolo Budroni, Library of the University of Vienna

Project Director, e-Infrastructures Austria; Coordinator, work sub-group; Secretary

Dipl.-Ing. Dr. Michaela Fritz, Medical University of Vienna

Vice-Rector for Research and Innovation

Dipl.-Ing. Raman Ganguly, Central Information Services, University of Vienna Technical Director, e-Infrastructures Austria

Dipl.-Ing. Florin Guma, IT-Services, University of Salzburg

Representative from university IT Services, e-Infrastructures Austria

e-lnfrastructures Austria: http://phaidra.univie.ac.at/o:459162; last accessed 5 February 2017. 
Dipl.-Ing. (FH) Manfred Halver, FFG, European and International Programmes

Research funding

Dr. Peter Kraker, Know-Center ${ }^{12}$

Representative from the scientific community, Representative from OANA

Mag. Wolfgang Nedobity, UNIKO

General Secretary of the Austrian Universities Conference (UNIKO)

Mag. iur. Sabine Ofner, Federal Ministry of Science, Research and Economics

Mag. Eva Ramminger, University and State Library of Tyrol, University of Innsbruck

Deputy Chair of the General Assembly, e-Infrastructures Austria

Ao. Univ. Prof. Dr. Andreas Rauber, Vienna University of Technology

Representative from the scientific community

Dr. Falk Reckling, FWF

Research funding

Mag. Barbara Sánchez Solís, Library of the University of Vienna

Project coordinator, e-Infrastructures Austria

Dipl.-Ing. Dr.techn. Maximilian Sbardellati, University of Music and Performing Arts Vienna

Representative from university IT Services, e-Infrastructures Austria

MinRat Peter Seitz, Federal Ministry of Science, Research and Economics

Mag. Sandra Vidoni, University of Klagenfurt

Representative from university Research Services

Mag. Michela Vignoli, Austrian Institute of Technology (A/T)

Representative from the scientific community

MinRat Daniel Weselka, Federal Ministry of Science, Research and Economics

This project has received funding from the European Union's Horizon 2020 research and innovation programme under grant agreement No 654139.

12 The Know-Center is funded within the Austrian COMET program - Competence Centers for Excellent Technologies - under the auspices of the Austrian Federal Ministry of Transport, Innovation and Technology, the Austrian Federal Ministry of Science, Research and Economy, and the State of Styria. COMET is managed by the Austrian Research Promotion Agency FFG. 